\title{
Decline after immobilisation and recovery after remobilisation of synovial fluid IL1, TIMP, and chondroitin sulphate levels in young beagle dogs
}

Department of Surgery, Kuopio University Hospital, Finland

J Haapala

Department of Physical and Rehabilitation Medicine, Kuopio University Hospital J P A Arokoski

Department of Anatomy, University of Kuopio, Finland S Rönkkö

U Ågren

M Tammi

H J Helminen

Department of Pathology and

Forensic Medicine, University of Kuopio

V-M Kosma

Department of Orthopaedics, University of Lund, Lund, Sweden

L S Lohmander

Department of Surgery, Jyväskylä Central Hospital, Jyväskylä, Finland

I Kiviranta

Correspondence to: Dr J Haapala, Päijät-Häme Central Hospital, Harjukatu 48, FIN-15110 Lahti, Finland

Jussi.Haapala@phks.fi

Accepted for publication 26 April 2000

J Haapala, J P A Arokoski, S Rönkkö, U Ågren, V-M Kosma, L S Lohmander, M Tammi, H J Helminen, I Kiviranta

\begin{abstract}
Objective-To monitor the concentration of markers of cartilage and synovium metabolism in the knee (stifle) joint synovial fluid of young beagles subjected to immobilisation and subsequent remobilisation.
\end{abstract}

Methods-The right hind limb of 17 dogs was immobilised in flexion for 11 weeks. Simultaneously, the contralateral left knee was exposed to increased weight bearing. The remobilisation period lasted 50 weeks. Litter mates served as controls. The concentration in joint lavage fluid of interleukin $1 \alpha$ (IL1 $\alpha$ ) was measured by immunoassay, the activity of phospholipase $A_{2}\left(P L A_{2}\right)$ was determined by an extraction method, chondroitin sulphate (CS) concentration by precipitation with Alcian blue, hyaluronan (HA) by an ELISA-like assay using biotinylated HAbinding complexes, matrix metalloproteinase 3 (MMP-3), and tissue inhibitor of metalloproteinases 1 (TIMP-1) by sandwich ELISA, and synovitis was scored by light microscopy.

Results-Synovitis or effusion was absent in all experimental and control groups. Immobilisation decreased the joint lavage fluid levels of IL1a $(p<0.05)$, TIMP ( $<<$ $0.05)$, and the concentration of CS down to $38 \%(p<0.05)$ in comparison with untreated litter mates with normal weight bearing. Immobilisation did not affect the activity of PLA $\mathrm{PA}_{2}$, or the concentration of MMP-3 or HA in synovial fluid. Joint remobilisation restored the decreased concentrations of markers to control levels. Increased weight bearing did not change the concentrations of markers in comparison with the control joints with normal weight bearing.

Conclusions-11 weeks' joint immobilisation decreased the concentration of markers of cartilage and synovium metabolism in the synovial fluid, and remobilisation restored the concentrations to control levels. The changes in joint metabolism induced by immobilisation, as reflected by the markers, are thus different from those found in osteoarthritis, where increased levels of these markers are associated with enhanced degradation and synthesis. These findings suggest that the change induced in joint metabolism by immobilisation is reversible in its early stages. (Ann Rheum Dis 2001;60:55-60)
Synovial fluid has a key role in diarthrodial joints by lubricating the moving cartilaginous and synovial surfaces and supplying nutrients to articular cartilage. ${ }^{1}$ The concentrations in synovial fluid of metabolic products of joint tissues are suggested to reflect tissue turnover of, and release from, the articular cartilage and other joint tissues. ${ }^{2}$

Neutral matrix metalloproteinases, like MMP-3, can cleave articular cartilage aggrecan, link protein, and collagen. ${ }^{3}$ Tissue inhibitor of metalloproteinases (TIMP) inhibits the activity of matrix metalloproteinases. ${ }^{4-6}$ Increased concentrations of metalloproteinases, and their tissue inhibitors have been detected in human osteoarthritis, in rheumatoid arthritis, ${ }^{7}$ and in early experimental osteoarthritis induced in beagles by tibial osteotomy. ${ }^{8}$ The activation of metalloproteinases can be initiated by cytokines such as interleukin 1 (IL1), whereas IL6 induces the synthesis of TIMP-1 but not of the metalloproteinases. ${ }^{9}{ }^{10}$ In experimental osteoarthritis, increased concentrations of cytokines have been detected in the synovial fluid. ${ }^{211}$

The inflammatory component is important in the pathogenesis of articular cartilage injury. ${ }^{12} 13$ In animals, intra-articular injection of phospholipase $\mathrm{A}_{2}\left(\mathrm{PLA}_{2}\right)$ induces acute synovitis. ${ }^{14}{ }^{15}$ The effect of PLA 2 is thought to be mediated through generation of arachidonic acid, which is converted to prostaglandins, potent mediators of inflammation. ${ }^{16}$ Increased concentrations of synovial type $\mathrm{PLA}_{2}$ have been found in osteoarthritis and rheumatoid arthritis. $^{8} 1718$

Hyaluronan (HA) provides lubrication and viscoelasticity to the synovial fluid. ${ }^{19}$ Joint immobilisation reduces HA concentration in articular cartilage. This change takes place simultaneously with a decrease of aggrecan in articular cartilage, suggesting that joint loading exerts a coordinated influence on their metabolism. ${ }^{20}$ The concentration of HA in synovial fluid is reduced in osteoarthritis and rheumatoid arthritis. ${ }^{21}$

Our study aimed at monitoring changes in the synovial fluid of beagle knee joints 11 weeks after joint immobilisation and after a subsequent remobilisation period of 50 weeks. Interest was focused on changes which would allow comparison between the synovial fluid marker changes in immobilisation-induced atrophy and experimental osteoarthritis. ${ }^{8}$ The effects of increased weight bearing on the contralateral limb were also investigated. Earlier observa- 
tions have suggested that the initial 11 week joint immobilisation followed by a 50 week remobilisation period causes local changes in the cartilage concentration of HA and proteoglycans, and in biomechanical properties of articular cartilage. ${ }^{202-24}$ Therefore, it seems possible that the 11 week immobilisation period may result in permanent changes in the properties of articular cartilage..$^{202-24}$

\section{Material and methods}

ANIMALS

Thirty four female pure bred beagle dogs (Marshall Farms, North Rose, NY, USA) were used in this experiment. The dogs lived in steel cages $(0.9 \times 1.2 \times 0.8 \mathrm{~m})$ in the National Laboratory Animal Centre (Kuopio, Finland). They were fed with commercial dog food (Hankkija, Kolppi, Finland) and water. The dogs were treated in accordance with the principles presented in the National Research Council's Guide for the Care and Use of Laboratory Animals. ${ }^{25}$ The Animal Care and Use Committee of the University of Kuopio approved the design of this experiment.

IMMOBILISATION AND REMOBILISATION AND INCREASED WEIGHT BEARING

The right hind limb of 17 dogs was immobilised at the age of 29 weeks for 11 weeks. The knee (stifle) joint was casted with fibreglass cast (Dynacast Pro, Smith and Nephew Medical, Hull, UK) in $90^{\circ}$ flexion. The casted limb was tied to the trunk to avoid weight bearing by the immobilised limb. Each splinted dog had a litter mate sister dog as a control. At the age of 40 weeks, eight splinted dogs and their controls were first anaesthetised with an intravenous bolus of thiopentone sodium (Hypnostan; Leiras, Turku, Finland) and radiographs were taken from the knee joints. The dogs were then killed with an overdose injection of pentobarbital (Mebunat, Orion, Espoo, Finland). At the same age, the casts were removed from another nine splinted dogs, and after a 50 week remobilisation period new radiographs were taken, and the dogs were killed as described above.

Splinting of the hind limb causes increased weight bearing in the opposite hind limb. Normally, when the dog uses four legs, the two hind limbs carry about $35 \%$ of the body weight at standing position, resulting in $17.5 \%$ of the total body weight for each leg (Haapala J, Lyyra $\mathrm{T}$, unpublished data). When the dog is jogging at a speed of $5 \mathrm{~km} / \mathrm{h}$, each hind limb carries proportionally more weight than at the standing position. A dog walking $(2.5 \mathrm{~km} / \mathrm{h})$ or jogging $(5 \mathrm{~km} / \mathrm{h})$ with one limb splinted carries $44-66 \%$ of the total body weight on the functional hind limb. ${ }^{26}$

\section{SYNOVIAL FLUID SAMPLES}

Synovial fluid samples were taken by lavage from the splinted, remobilised, and contralateral knee joints, as well as from the knee joints of the control dogs. After the dogs were killed the knee joint was surgically exposed to the level of joint capsule and $3 \mathrm{ml}$ sterile physiological saline was injected through the capsule into the knee joint. The joint was fully extended and flexed 10 times, and thereafter all fluid was collected. The volume of the joint lavage fluid was measured and stored in Eppendorf tubes, at $-70^{\circ} \mathrm{C}$, until analysed.

ASSAY OF INTERLEUKIN $1 \alpha$ (IL1 $\alpha)$

The concentration of IL $1 \alpha$ in the synovial fluid was determined quantitatively by an immunoassay with a monoclonal antibody (Immunoenzymometric assay kit, Immunotech s.a., Marseille, France). Samples and standards were incubated in wells of a microtitre plate coated with the first monoclonal antibody, directed against IL1 $\alpha$. After aspiration and washing, a second monoclonal anti-IL1 $\alpha$ antibody was added to the wells; this latter antibody was conjugated with acetylcholinesterase. After incubation, the wells were aspirated, rinsed, and the retaining enzymatic activity was determined by the addition of a chromogenic substrate for the acetylcholinesterase. The intensity of the colour is proportional to the IL $1 \alpha$ concentration in the samples and standards. ${ }^{27} 28$

ASSAY OF SYNOVIAL TYPE PHOSPHOLIPASE A $\left(\mathrm{PLA}_{2}\right)$

The enzyme activity of $\mathrm{PLA}_{2}$ in the synovial fluid was measured with 1-palmitoyl-2-(1$\left.{ }^{14} \mathrm{C}\right)$ linoneoyl-L-3-phosphatidylethanolamine (lino-PE; 59 mCi/mmol; Amersham, England) as substrate. ${ }^{29}$ The standard assay mixture contained 0.1 M Tris- $\mathrm{HCl}$ buffer ( $\mathrm{pH} 9.0), 5 \mathrm{mM}$ $\mathrm{CaCl}_{2}, 0.5 \mathrm{mM}$ sodium deoxycholate, $2.24 \mu \mathrm{M}$ lino-PE, and $25 \mu \mathrm{l}$ synovial fluid in a volume of $300 \mu \mathrm{l}$. The incubations were carried out for 60 minutes in a water bath at $37^{\circ} \mathrm{C}$. The reaction was stopped with $1.25 \mathrm{ml}$ of Dole extraction mixture (2-propanol:n-heptane:0.5 M aqueous sulphuric acid 40:10:1 v/v). The radioactivity was counted in a liquid scintillation counter (LKB Wallac, Turku, Finland). All results reported are mean values of duplicate analyses.

MEASUREMENT OF CHONDROITIN SULPHATE (CS) Measurement was performed by precipitation of CS with Alcian blue, as described by Björnsson. ${ }^{30}$ The specificity for CS was achieved by using low pH $(<2.0)$ in combination with detergent and high salt concentration with $1.0 \mathrm{M}$ guanidine- $\mathrm{HCl} .^{30}$ Non-sulphated polyanions were excluded by lowering the $\mathrm{pH}$, and hydrophobic interactions of proteins with Alcian blue were minimised by the detergent. ${ }^{30}$

\section{MEASUREMENT OF HYALURONAN (HA)}

Synovial fluid HA was measured by an ELISAlike assay using biotinylated HA-binding complexes (bHABC) prepared from the proteoglycan link protein complex of bovine articular cartilage. $^{31} 32$ Briefly, Nunc Covalink tubes (Covalink, Nunc, Roskilde, Denmark) were coated with HA $(50 \mu \mathrm{g} / \mathrm{ml}$, Sigma, St Louis, MO, USA) and blocked with $1 \%$ bovine serum albumin (BSA). The samples were first digested with papain $(250 \mu \mathrm{g} / \mathrm{ml}$ in $5 \mathrm{mM}$ cysteine, $5 \mathrm{mM}$ EDTA, Sigma) at $60^{\circ} \mathrm{C}$ for 24 hours and the enzyme was then inactivated by boiling for 10 minutes. The digested samples 
and a series of standard HA (5-200 ng/ml) diluted in $6 \% \mathrm{BSA}$ in phosphate buffered saline (PBS) were mixed with an equal volume of bHABC $(450 \mathrm{ng} / \mathrm{ml})$ in small polypropylene tubes (Mekalasi, Kuortane, Finland) and incubated overnight at $4^{\circ} \mathrm{C}$. Immediately before the assay the mixtures were incubated for one hour at $37^{\circ} \mathrm{C}$. The samples and standards were then transferred to the HA precoated plates, incubated for 90 minutes at $37^{\circ} \mathrm{C}$, and washed with $0.5 \%$ Tween 20 in PBS. Horseradish peroxidase conjugated streptavidin (1:20 000 in PBS, Vector Laboratories, Burlingame, CA, USA) was added to the plates and left for one hour at $37^{\circ} \mathrm{C}$. After washing, the substrate-chromogen solution ( $O$-phenylenediamine dihydrochloride; Sigma, $0.03 \% \mathrm{H}_{2} \mathrm{O}_{2}$ in $0.1 \mathrm{M}$ citrate buffer, $\mathrm{pH}$ 5.0) was added and left for one hour. The reaction was stopped with $8 \mathrm{M}$ $\mathrm{H}_{2} \mathrm{SO}_{4}$ and the absorbances were read at 490 $\mathrm{nm}$ using a microtitre plate reader (Molecular Devices Corporation, Palo Alto, CA, USA). All results reported are mean values of duplicate analyses.

ASSAYS OF STROMELYSIN (MMP-3) AND TISSUE INHIBITOR OF METALLOPROTEINASES (TIMP) MMP-3 and TIMP concentrations in synovial fluid were determined by sandwich ELISA, using monoclonal and polyclonal antibodies raised against human recombinant proteins. All assays use a monoclonal antibody against the enzyme or inhibitor as a trapping reagent. ${ }^{33}$ Polyclonal antisera against specific proteins generated in rabbits were used as secondary reagents. ${ }^{33}$ For TIMP ELISA, the mouse antihuman TIMP monoclonal antibody, Mac 019, was added to the wells as a trapping reagent, $0.05 \mathrm{mg} /$ well. The second antibody was an IgG fraction of rabbit antihuman TIMP antiserum used at $0.05 \mathrm{mg} /$ well. The assay was developed by incubating the plates with horseradish peroxidase conjugated sheep antirabbit IgG followed by tetramethylbenzidine. ${ }^{34}{ }^{35}$

The assay for MMP-3 detects the proforms of the enzyme, the high molecular weight active forms of the enzymes, and the enzymes complexed to TIMP, but not small molecular weight forms or enzymes complexed to $\alpha_{2}$ macroglobulin. The assay for TIMP, as used in this investigation, detects only free TIMP. The stromelysin assay has a log-linear range of $0.5-100 \mathrm{ng} / \mathrm{ml}$, and the TIMP assay $0.8-30 \mathrm{ng} /$ $\mathrm{ml} .^{633-35}$
SCORING SYNOVITIS BY LIGHT MICROSCOPY One synovial membrane specimen/dog was taken from the anterolateral joint capsule close to its insertion onto the tibia. The samples were fixed in $4 \%$ formaldehyde solution in phosphate buffer ( $\mathrm{pH} 7.0,0.013 \mathrm{M}$ ), embedded in paraffin, sectioned at $5 \mu \mathrm{m}$, and stained with haematoxylin and eosin. The sections of synovium were screened by light microscopy, and the greatest number of inflammatory cells (polymorphonuclear leucocytes, lymphocytes, and macrophages) was estimated. Absent inflammation was scored as 0 , grade 1 was assigned to slight, and grade 2 to moderate or dense number of inflammatory cells in the samples.

STATISTICAL ANALYSIS

The two tailed non-parametric Wilcoxon's matched pairs signed ranks test was used for statistical analysis.

\section{Results}

RADIOGRAPHS

Radiographs of the knee joints showed no abnormalities in the bony structures or in the width of the joint space in any of the experimental or control dogs.

\section{VOLUME OF SYNOVIAL FLUID}

No effusion was seen in the knee joints in any group examined after the dogs were killed. An average of $2.9(0.2) \mathrm{ml}$ (mean (SD)) joint lavage fluid was collected from the knee joints after injection of $3.0 \mathrm{ml}$ saline. The experimental groups did not differ from each other in this respect.

\section{EFFECT OF IMMOBILISATION AND}

REMOBILISATION ON SYNOVIAL FLUID MEDIATORS Immobilisation with a splint decreased the concentration of IL $1 \alpha$ in synovial fluid to $22 \%$ of the control value in dogs with normal weight bearing $(p<0.05)$ (table 1$)$. After the remobilisation period the concentration of IL $1 \alpha$ was comparable with the levels seen in contralateral and control joints. Immobilisation, increased weight bearing, or remobilisation did not alter the concentration of MMP-3 or activity of $\mathrm{PLA}_{2}$ (table 1).

After immobilisation the concentration of TIMP-1 was $87 \%(p<0.05)$ of the control value, but remobilisation restored it. Increased

Table 1 Synovial fluid markers after a remobilisation period of 50 weeks following prior immobilisation of the right knee joint for 11 weeks

\begin{tabular}{|c|c|c|c|c|c|c|}
\hline \multirow[b]{2}{*}{ Marker } & \multicolumn{3}{|c|}{ Beagles 40 weeks of age } & \multicolumn{3}{|c|}{ Beagles 90 weeks of age } \\
\hline & $\begin{array}{l}\text { Immobilised } \\
(n=7)\end{array}$ & $\begin{array}{l}\text { Contralateral } \\
(n=7)\end{array}$ & $\begin{array}{l}\text { Control } \\
(n=7)\end{array}$ & $\begin{array}{l}\text { Remobilised } \\
(n=7)\end{array}$ & $\begin{array}{l}\text { Contralateral } \\
(n=7)\end{array}$ & $\begin{array}{l}\text { Control } \\
(n=9)\end{array}$ \\
\hline Interleukin $1 \alpha(\mathrm{pg} / \mathrm{ml})$ & $0.8(1.0)^{\star}$ & $1.4(2.6)$ & $3.6(3.1)$ & $2.8(2.9)$ & $2.3(2.9)$ & $1.7(1.1)$ \\
\hline Phospholipase $\mathrm{A}_{2}(\mathrm{pmol} / \mathrm{min} / \mathrm{ml})$ & $21.2(10.1)$ & $20.9(5.6)$ & $20.4(4.9)$ & $21.7(8.9)$ & $15.9(2.1)$ & $23.5(16.5)$ \\
\hline MMP-3† (nmol/1) & $1.4(0.3)$ & $1.8(0.7)$ & $1.8(0.5)$ & $2.1(2.0)$ & $2.0(0.7)$ & $2.1(1.2)$ \\
\hline TIMP-1† (nmol/1) & $1.3(0.5)^{\star}$ & $1.9(1.2)$ & $1.5(0.5)$ & $0.8(0.1)$ & $0.8(0.2)$ & $0.9(0.4)$ \\
\hline MMP-3/TIMP-1 & $1.3(0.5)$ & $1.3(0.5)$ & $1.4(0.8)$ & $2.7(1.1)$ & $2.6(0.8)$ & $2.4(1.0)$ \\
\hline
\end{tabular}

Values indicate mean (SD) in each group. The two tailed non-parametric Wilcoxon's matched pairs signed ranks test was used for statistical analysis.

${ }^{\star} \mathrm{p}<0.05$ compared with controls.

†MMP-3 = matrix metalloproteinase 3; TIMP-1 = tissue inhibitor of metalloproteinases 1. 
Table 2 Synovial fluid chondroitin sulphate and hyaluronan after a remobilisation period of 50 weeks following prior immobilisation of the right knee joint for 11 weeks

\begin{tabular}{|c|c|c|c|c|c|c|}
\hline & \multicolumn{3}{|c|}{ Beagles 40 weeks of age } & \multicolumn{3}{|c|}{ Beagles 90 weeks of age } \\
\hline & $\underset{(n=8)}{\text { Immobilised }}$ & $\begin{array}{l}\text { Contralateral } \\
(n=8)\end{array}$ & $\begin{array}{l}\text { Control } \\
(n=8)\end{array}$ & $\begin{array}{l}\text { Remobilised } \\
(n=9)\end{array}$ & $\begin{array}{l}\text { Contralateral } \\
(n=9)\end{array}$ & $\begin{array}{l}\text { Control } \\
(n=9)\end{array}$ \\
\hline Chondroitin sulphate $(\mu \mathrm{g} / \mathrm{ml})$ & $2.3(0.5)^{\star}$ & $9.0(5.0)$ & $6.1(1.3)$ & $5.4(1.7)$ & $5.4(2.0)$ & $6.1(3.1)$ \\
\hline Hyaluronan $(\mu \mathrm{g} / \mathrm{ml})$ & $339(189)$ & $415(100)$ & $469(152)$ & $351(143)$ & $393(221)$ & $290(186)$ \\
\hline
\end{tabular}

Values indicate mean (SD) in each group. The two tailed non-parametric Wilcoxon's matched pairs signed ranks test was used for statistical analysis.

${ }^{\star} \mathrm{p}<0.05$ compared with controls.

weight bearing did not induce any statistically significant changes in the concentration of TIMP-1 in the synovial fluid (table 1).

IMMOBILISATION AND REMOBILISATION EFFECTS ON THE CONCENTRATION OF CS AND HA IN SYNOVIAL FLUID

The CS concentration was $62 \% \quad(p<0.05)$ lower in the synovial fluid lavages of the immobilised joints than in the controls. Remobilisation restored the decreased concentration of CS seen after immobilisation. Increased weight bearing did not alter significantly the concentration of synovial fluid CS. Increased load bearing in the contralateral joint did not alter the concentration of HA (table 2).

\section{GRADE OF SYNOVITIS}

No synovitis was seen (grade 0 ) after immobilisation, and synovitis was also absent in control animals and after increased weight bearing. After remobilisation all synovium samples had a normal appearance (grade 0).

\section{Discussion}

The concentration of markers in the synovial fluid is determined by the rate of their release from cartilage and synovium into the joint cavity relative to the clearance of synovial fluid. ${ }^{36}$ The clearance rates of $\mathrm{HA}$, proteoglycans, and large proteoglycan fragments seem to differ from those of water and albumin, as the former substances are partially retained in the joint cavity by the synovial lining. ${ }^{37} 38$ This implies that during muscle contractions, HA, proteoglycans, and their fragments will impact in the intimal matrix and impede the passage of HA, smaller molecular weight compounds, and even water from the joint cavity. ${ }^{37-39}$ The removal of material - for example, blood, from the joint cavity is delayed by immobilisation because the synovial lymph flow depends on joint movements. ${ }^{1}$ Thus, in principle, gradual increase of the synovial fluid volume can result from joint immobilisation. ${ }^{1}$ However, in this study no increase was recorded in the volume of joint lavage fluids after immobilisation.

Immobilisation of the knee joint in flexion for 11 weeks decreased the concentrations of IL1 $\alpha$, TIMP-1, and CS in the synovial fluid, whereas MMP-3 stayed at the control level or slightly below. The reduced IL $1 \alpha$ levels in the synovial fluid suggest that an inflammatory reaction was not active at the time synovial fluid samples were collected. This is in line with the observation that also the levels of $\mathrm{PLA}_{2}$, a marker of inflammation, were not changed. In addition, microscopic examination of the synovium did not disclose any signs of synovitis. These observations are in contrast with those obtained after induction of canine osteoarthritis by tibial valgus osteotomy. ${ }^{8}$ After osteotomy, an increase in the concentrations of synovial fluid PLA $\mathrm{P}_{2}$, TIMP, and MMP-3 was recorded, and CS showed an upward trend. ${ }^{8}$ The assays were the same as used in this study. Microscopic signs of osteoarthritis were also seen. ${ }^{8}$ These changes were not present after immobilisation. Thus it is apparent that a more quiescent metabolism is established during the cartilage atrophy that develops after joint immobilisation, manifesting itself also in the composition of the synovial fluid.

The immobilisation-induced decrease of CS in the synovial fluid reflected, most probably, the reduced content of proteoglycans in articular cartilage, and their flux through the synovial fluid after release and partial fragmentation. ${ }^{22} 4041$ In an earlier study we showed that after 11 weeks' joint immobilisation the incorporation of ${ }^{35} \mathrm{SO}_{4}$ into the articular cartilage explants was maintained at the control level at the same time as the local concentration of proteoglycans in the cartilage tissue was significantly decreased. ${ }^{23}$ This suggests enhanced proteoglycan breakdown instead of reduced synthesis during joint immobilisation. ${ }^{23}$ An increase of metalloproteinase levels in the cartilage in comparison with TIMPs would explain the decrease of cartilage proteoglycans after immobilisation. In this study the concentration of TIMP-1 in synovial fluid was reduced by immobilisation, but the molar ratio of MMP-3 and TIMP-1 was not significantly altered (table 1). However, Grumbles et al reported that after four weeks of sling immobilisation there was an increase of proteases and a depression of TIMPs in the disuse atrophy of canine knee cartilages. ${ }^{42}$ In rheumatoid human synovial cells IL $1 \alpha$ induces the synthesis of metalloproteinases but not of TIMP- $1 .{ }^{43} \mathrm{In}$ flammatory episodes are part of the natural course of cartilage destruction in rheumatoid arthritis and osteoarthritis. ${ }^{6} 7$ IL1 and tumour necrosis factor $\alpha$ are the key cytokines in arthritis. ${ }^{44}$ The possibility cannot be ruled out that IL $1 \alpha$ levels of cartilage increased transiently during the first weeks of immobilisation. This would explain the reduction of proteoglycans and cartilage atrophy.

In a series of experiments on canine osteoarthritis by Ratcliffe et al, synovial fluid samples were shown to contain increased levels of the native chondroitin sulphate epitope (3-B-3), keratan sulphate epitope, sulphated glycosaminoglycan, and link protein. ${ }^{45}$ However, 
when examined with the same assays, the fluid from joints with disuse atrophy showed increased levels only of keratan sulphate epitope and sulphated glycosaminoglycan. ${ }^{46}$ Also, these results suggest that the metabolism of proteoglycans in articular cartilage during early osteoarthritis and disuse atrophy are different. $^{45-47}$

In our study no changes in the concentration of HA in the synovial fluid were seen. Earlier, we found reduced concentrations of both HA and aggrecan in the articular cartilage after immobilisation. ${ }^{20}$ Because HA comprises only about $2.3-6.3 \%$ of total glycosaminoglycans in canine cartilage, and immobilisation causes $16-27 \%$ decrease of $\mathrm{HA}$ in cartilage, ${ }^{20}$ it is not surprising that this small change cannot be detected in the synovial fluid, particularly because the synovial fibroblastic cells, and not the chondrocytes, are the main source of HA in synovial fluid. ${ }^{136}{ }^{39}$ In sheep, immobilisation of the joint for five months did not significantly reduce the ability of the synovial cells to produce HA. ${ }^{39}$ Therefore, it is understandable that the level of HA in the synovial fluid and its metabolism in the articular cartilage follow different patterns. CS in the synovial fluid represents proteoglycans or their fragments, or both. ${ }^{2}{ }^{40}$ The decrease in the synovial fluid concentration of CS, and the previously noted reduction of aggrecan in cartilage tissue, ${ }^{22}$ probably reflect an altered metabolism of aggrecan after joint immobilisation. In contrast with the present immobilisation model, the synthesis and turnover of articular cartilage proteoglycans is increased in the early phase of osteoarthritis, ${ }^{48}{ }^{49}$ and there is a positive correlation between the severity of the disease and the concentration of proteoglycans and/or their fragments in synovial fluid. ${ }^{41}$

After remobilisation, the activity of $\mathrm{PLA}_{2}$ and the concentrations of IL1 $\alpha$, MMP-3, TIMP-1, $\mathrm{CS}$, and HA in synovial fluid did not differ from control values. Evidently, normal joint loading brought the values back to the control level. Neither did the values from the contralateral knee joint, exposed to increased weight bearing during immobilisation, differ from control values, though the concentration of CS showed a (statistically non-significant) upward trend (table 2). This upward trend might reflect an accelerated synthesis and/or release of proteoglycans and/or their fragments from cartilage because we have earlier shown that increased weight bearing can increase the local concentration of glycosaminoglycans in articular cartilage. ${ }^{50}$

However, we have also noted that the concentration of proteoglycans remains low in certain cartilage locations after the remobilisation period. ${ }^{22}$ The decreased proteoglycan concentration in articular cartilage was detected in the superficial and intermediate zones on the summit of the medial femoral condyle and in the plateau of the medial condyle of tibia. Those areas represent a small part of the total cartilage area in the beagle knee joint, and an even smaller proportion of the total articular cartilage volume. Therefore, a synovial fluid analysis at a single time point 50 weeks after the remobilisation was started, is not likely to disclose focal changes affecting a small proportion of the joint cartilage especially because the associated metabolic events might have occurred much earlier.

The results of this study support the view that reduced joint loading by immobilisation creates an altered equilibrium in cartilage proteoglycan and HA metabolism, which manifests itself also in reduced concentrations of cartilage products in the synovial fluid. ${ }^{45-47}$ Our earlier results of the effects of joint immobilisation on articular cartilage corroborate this interpretation of reduced matrix turnover. $^{20223}$ The alterations seen after joint immobilisation in the markers of synovial fluid are different from those seen in experimental canine osteoarthritis. ${ }^{8424647}$ This study was supported by grants from the Finnish Cultural
Foundation and the Ministry of Education in Finland, the Swedish Medical Research Council, the King Gustaf V 80-year fund, and the Medical Faculty and University Hospital in Lund.

1 Levick JR. Synovial fluid and trans-synovial flow in stationary and moving normal joints. In: Helminen HJ, Kiviranta I, Tammi M, Säämänen A-M, Paukkonen K, Jurvelin J, eds. foint loading. Biology and health of articular structures. Bristol: Wright, 1987:149-86.

2 Lohmander LS. What is the current status of biochemical markers in the diagnosis, prognosis and monitoring of osteoarthritis? In: Bellamy N, ed. Osteoarthritis. Baillieres osteoarthritis? In: Bellamy N, ed.
Clin Rheumatol 1997;11:711-26.

3 Wu J-J, Lark MW, Chun LE, Eyre DR. Sites of stromelysin cleavage in collagen types II, IX, X, and XI of cartilage. J

4 Brinckerhoff C. Joint destruction in arthritis: metalloproteiBrinckerhoff C. Joint destruction in arthritis: metalloprote-
nases in the spotlight. Arthritis Rheum 1991;34:1073-5.

5 Flannery CR, Lark MW, Sandy JD. Identification of a stromelysin cleavage site within the interglobular domain of human aggrecan - evidence for proteolysis at this site in vivo in human articular cartilage. J Biol Chem 1992;267: 1008-14.

6 Lohmander LS, Hoerrner LA, Lark MW. Metalloproteinases, tissue inhibitor, and proteoglycan fragments in knee synovial fluid in human osteoarthritis. Arthritis Rheum 1993;36:181-9.

7 Clark I, Powell L, Ramsey S, Hazleman B, Cawston T. The measurement of collagenase, tissue inhibitor of metalloproteinases (TIMP), and collagenase-TIMP complex in synovial fluids from patients with osteoarthritis and rheumatoid vial fluids from patients with osteoarthritis
arthritis. Arthritis Rheum 1993;36:372-9.

8 Panula H, Lohmander S, Rönkkö S, Ågren U, Helminen HJ, Panula H, Lohmander S, Rönkkö S, Agren U, Helminen HJ,
Kiviranta I. Elevated levels of synovial fluid PLA2, stromelysin (MMP-3) and TIMP in early osteoarthrosis after tibial valgus osteotomy in young beagle dogs. Acta Orthop

Scand 1998;69:152-8.
9 Hutchinson NI, Lark MW, McNaul KL, Harper C, Hoerner LA, McDonnell J. In vivo expression of stromelysin in synovium and cartilage of rabbits injected intra-articularly with interleukin $1 \beta$. Arthritis Rheum 1992;35:1227-33.

10 Lotz M, Guerne P. Interleukin-6 induces the synthesis of tissue inhibitor of metalloproteinases-1/erythroid potentiating activity (TIMP-1/EPA). J Biol Chem 1991;266: 2017-20.

11 Venn G, Nietfeld JJ, Duits AJ, Brennan FM, Arner E, Covington $\mathrm{M}$, et al. Elevated synovial fluid levels of interleukin-6 and tumor necrosis factor associated with early experimental osteoarthritis. Arthritis Rheum 1993; 36:819-26.

12 Revell P, Mayston V, Lalor P, Mapp P. The synovial membrane in osteoarthritis: a histological study including
the characterization of the cellular infiltrate present in the characterization of the cellular infiltrate present in Anflammatory osteoarthritis using

13 Shinmei M, Masuda K, Kikuchi T, Shinomura Y. The role of cytokines in chondrocyte mediated cartilage degradation: protective effect of NSAID. J Rheumatol 1989;16 (suppl 18):19-27.

4 Bomalaski J, Lawton P, Browning J. Human extracellular recombinant phospholipase A2 induces inflammatory response in rabbit joints. J Immunol 1991;146:3904-10.

15 Vadas P, Pruzanski W, Kim J, Fornasier V. The proinflammatory effect of intra-articular injection of soluble human and venom phospholipase $A_{2}$. Am J Pathol 1989;134:80711 .

16 Vadas P, Stefanski E, Pruzanski W. Characterization of extracellular phospholipase A2 in rheumatoid synovial extracellular phospholipase A2
fluid. Life Sci 1985;36:579-87.

17 Kortekangas P, Aro H, Nevalainen T. Group II phospholipase A2 in synovial fluid and serum in acute arthritis. pase A2 in synovial fluid and ser

18 Pruzanski W, Vadas P, Stefanski E, Urowitz M. Phospholipase A2 activity in sera and synovial fluid in rheumatoid 
arthritis and osteoarthritis. Its possible role as a proinflammatory enzyme. J Rheumatol 1985;12:211-16.

19 Ogston A, Steiner J. The physiological function of hyaluronic acid in synovial fluid: viscous, elastic and lubricant properties. J Physiol 1953;119:244-52.

20 Haapala J, Lammi M J, Inkinen R, Parkkinen JJ, Ågren UM, Arokoski J, et al. Coordinated regulation of hyaluronan and aggrecan content in the articular cartilage of immobilized and exercised dogs. J Rheumatol 1996;23:1586-93.

21 Dahl L, Dahl I, Engström-Laurent A, Granath K. Concentration and molecular weight of sodium hyaluronate in synovial fluid from patients with rheumatoid arthritis and other arthropathies. Ann Rheum Dis 1985;44:817-22.

22 Jortikka MO, Inkinen RI, Tammi MI, Parkkinen JJ, Haapala $\mathrm{J}$, Kiviranta I, et al. Immobilisation causes longlasting matrix changes both in the immobilised and contralateral cartilage. Ann Rheum Dis 1997;56:255-61.

23 Haapala J, Arokoski JPA, Hyttinen MM, Lammi M, Tammi $\mathrm{M}$, Kovanen $\mathrm{V}$, et al. Remobilization does not fully restore immobilization induced articular cartilage atrophy. Clin Orthop 1999;362:218-29.

24 Haapala J, Arokoski J, Pirttimäki J, Lyyra T, Jurvelin J, Tammi $M$, et al. Incomplete restoration of immobilization induced tion. Int J Sports Med 2000;21:76-81

25 NIH: Institute of Laboratory Animal Resources, National Research Council. Guide for care and use of laboratory animals. Bethesda: US Government Printing Office, 1985. (NIH publication No 78-23.)

26 Heikkinen LM, Panula HE, Lyyra T, Olkkonen H, Kiviranta I, Nevalainen T, et al. Electromechanical film sensor device for dynamic force recording from canine limbs. Scandinavian Journal of Animal Science 1997;24:85-92.

27 Grassi J, Frobert Y, Pradelles P, Chercuitte F, Gruaz D, Dayer JM, et al. Production of monoclonal antibodies against interleukins $1 \alpha$ and $1 \beta$ : development of two enzyme immunometric assays (EIA) using acetylcholinesterase and application to biological media. J Immunol Methods 1989; 123:193-210

28 Pradelles P, Grassi J, Maclouf J. Enzyme immunoassay of eicosanoids using acetylcholinesterase as a label: an lternative to radioimmunoassay. Anal Chem 1985:57: 1170-3.

29 Rönkkö S, Lahtinen R, Vanha-Perttula T. Phospholipases A in the reproductive system of the bull. Int J Biochem 1991 23:595-603.

30 Björnsson S. Simultaneous preparation and quantification of proteoglycans by precipitation with Alcian blue. Anal Biochem 1993;210:282-91.

31 Wang C, Tammi M, Tammi R. Distribution of HA and its CD44 receptor in the epithelia of human skin appendages. Histochemistry 1992;98:105-12.

32 Kongtawelert P, Ghosh P. A method for the quantitation of hyaluronan (hyaluronic acid) in biological fluids using a labelled avidin-biotin technique. Anal Biochem 1990;185: 313-18.

33 Cooksley S, Hipkiss JB, Tickle SP, Holmes-Ievers E, Docherty AJ, Murphy G, et al. Immunoassays for the Docherty AJ, Murphy $G$, et al. Immunoassays for the detection of human collagenase, stromelysin, tissue inhibitor of metalloproteinases (TIMP)

34 Walakovits LA, Moore VL, Bhardwaj N, Gallick GS, Lark MW. Detection of stromelysin and collagenase in synovia fluid from patients with rheumatoid arthritis and posttraumatic knee injury. Arthritis Rheum 1992;35:35-42.
35 Bayne EK, Hutchinson NI, Walakovits LA, Donatelli S, MacNaul KL, Harper CF, et al. Production, purification and characterization

36 Levick JR, Price FM, Mason RM. Synovial matrix-synovial fluid system of joints. In: Comper WD, ed. Extracellular matrix. Vol 1. Amsterdam: Harwood Academic, 1996:328-

37 Coleman PJ, Scott D, Ray J, Mason RM, Levick JR. Hyaluronan secretion into the synovial cavity of rabbit knees and comparison with albumin turnover. J Physiol (Lond) 1997;503(pt 3):645-56.

38 Scott D, Coleman PJ, Mason RM, Levick JR. Glycosaminoglycan depletion greatly raises the hydraulic permeability of rabbit joint synovial lining. Exp Physiol 1997;82:603-6.

39 Edwards JCW. Synovial physiology in the context of osteoarthritis. In: Brandt KD, Doherty M, Lohmander LS, eds. Osteoarthritis. Oxford: Oxford University Press, 1998:167-75.

40 Lohmander LS, Neame P, Sandy J. The structure of aggrecan fragments in human synovial fluid: evidence that agrecanase mediates cartilage degradation in inflammatory joint disease, joint injury and osteoarthritis. Arthritis Rheum 1993; 36:1214-22.

41 Messner K, Gillquist J, Björnsson S, Lohmander L S. Proteoglycan fragments in rabbit joint fluid correlated to arthrosis stage. Acta Orthop Scand 1993;64:312-16.

42 Grumbles RM, Howell DS, Howard GA, Roos BA, Setton LA, Mow VC, et al. Cartilage metalloproteases in disuse atrophy. J Rheumatol 1995;22(suppl 43):146-8.

43 MacNaul K, Chartrain N, Lark M, Tocci M, Hutchinson N. Discoordinate expression of stromelysin, collagenase, and tissue inhibitor of metalloproteinases-1 in rheumatoid synovial fibroblasts. J Biol Chem 1990;265:17238-45.

44 van den Berg W. Joint inflammation and cartilage destruction may occur uncoupled. Springer Semin Immunopathol 1998;20:149-64.

45 Ratcliffe A, Shurety W, Caterson B. The quantitation of a native chondroitin sulfate epitope in synovial fluid lavages and articular cartilage from canine experimental osteoarthritis and disuse atrophy. Arthritis Rheum 1993;36:543-51.

46 Ratcliffe A, Beauvais P, Saed-Nejad F. Differential levels of synovial fluid aggregate components in experimental osteoarthritis and joint disuse. J Orthop Res 1994;12:464-73.

47 Müller FJ, Setton LA, Manicourt DH, Mow VC, Howell DS, Pita JC. Centrifugal and biochemical comparison of proteoglycan aggregates from articular cartilage in experimental joint disuse and joint instability. J Orthop Res 1994;12:498-508.

48 Carney SL, Billingham MEJ, Caterson B, Ratcliffe A, Bayliss MT, Hardingham TE, et al. Changes in proteoglycan turnover in experimental canine osteoarthritic cartilage. Matrix 1992;12:137-47.

49 Sandy JD, Adams ME, Billingham MEJ, Plaas A, Muir H. In-vivo and in-vitro stimulation of chondrocyte biosynthetic activity in early experimental osteoarthritis. Arthritis Rheum 1984;27:388-97.

50 Kiviranta I, Jurvelin J, Tammi M, Säämänen A-M, Helminen HJ. Weight-bearing controls glycosaminoglycan concentration and articular cartilage thickness in the knee joints of young beagle dogs. Arthritis Rheum 1987;30: $801-9$ 